Background Involving women in HIV programmes such as Prevention from Mother To Child Transmission of HIV is important because they are one of the most affected population groups. However, in rural settings PMTCT is a challenge lack easy access to health centres where they can be tested for HIV and for safer child births. This health service gap is filled-in by traditional birth attendants, who mostly lack adequate knowledge of HIV and how to prevent mother-child transmission.

Methods The Zambia Traditional Births Attendants Association conducted a workshop for Traditional Birth Attendants in the Eastern Province. 24 Traditional Birth Attendants, 5 chiefs and their wives, from 5 villages attended the workshop. Clinical staff from a health, approximately $150 \mathrm{Km}$ away facilitated. Pre-and post-workshop questionnaires were administered.

Results $80 \%$ of the participants were aware of HIV but were not sure how to prevent it. $20 \%$ believed HIV was due to witchcraft. $72 \%$ did not see the wearing protective gear when helping women in labour as important. $97 \%$ were ignorant of HIV basic science. 93\% had no idea of PMTCT. Myths and misconceptions included that children cannot get the HIV because they do not indulged in sex; that traditional medicine can treat and cure HIV/AIDS. The workshop noted the need to train Traditional Birth Attendants in PMTCT services counselling and oral rapid testing for HIV in pregnant women. The other need was training them how to administer single-dose Nevirapine to HIV positive pregnant women during labour and to their newborn babies.

Conclusion It is important to involve traditional birth attendant in HIV and PMTCT programmes stop the spread of HIV. Village health committees should be established were they do not exist and integrated with HIV and PMTCT services. Sustained provision of PMTCT and HIV testing kits, and follow-ups by health staff is needed.

\section{P17.45 ASSESSING THE USE OF A PEER-LED MOBILE VAN FOR EFFECTIVE HIV SERVICE DELIVERY IN REGIONAL QUEENSLAND: A WHOLE OF COMMUNITY APPROACH}

T Rudduck*, S Brown. Community HIV Education and Prevention (CHEP) Program Queensland Positive People

\subsection{6/sextrans-2015-052270.623}

Background While Queensland rates of HIV are increasing, regional Queenslanders have reduced access to HIV-related information, rapid testing and clinical services. Men who have sex with men are less likely to access services due to HIV-related stigma and discrimination. The aim of this project was to assess the effectiveness of using a peer-led mobile van for regional service delivery.

Methods Rapid Roadshow was a whole of population awareness-raising initiative of the CHEP program. In November 2014, two vans stopped at predetermined locations between Port Douglas and Gold Coast providing HIV information through discussion, resources, merchandise and quizzes, with rapid HIV and STI testing in some locations. Evaluation forms were provided to all rapid test participants.

Results HIV information was provided via 1696 resources and promotional items, 1094 condom packs and 427 conversations.

Of the 39 rapid HIV tests performed; $89.7 \%$ (35) participants identified as male, $61.5 \%(24)$ as non-heterosexual and 5 received STI screening.
37 participants completed evaluation forms; $72.9 \%$ (27) last tested over 6 months ago and 24.3\% (9) had never tested before. $75.7 \%$ (28) preferred a non-clinical setting for testing with $81 \%$ (30) identifying that they would test more frequently with rapid test availability.

Visits to www.endhiv.org.au increased by $298 \%$ (Nov - Jan), compared to the previous quarter (Aug - Oct), with the testing locator and quiz pages increasing by $49 \%$ and $138 \%$ respectively.

Conclusion We can assume that the increased website visits are attributed to online promotion during Rapid Roadshow.

While the sample size was small, the people tested for HIV identified an increased likelihood for continued testing with increased rapid testing availability outside of a clinical setting.

A more regular presence in regional Queensland will allow us to collect more data and maintain our online presence, while directly supporting regional areas with localised data.

Disclosure of interest statement The CHEP program and all projects of the CHEP program are funded by the HIV Foundation Queensland and hosted by Queensland Positive People. Financial support was provided by Alere for the Rapid Roadshow project.

\section{P18 - HIV prevention and social aspects}

\section{P18.01 PREGNANCY WITH HIV INFECTION CONDITION AFTER PMTCT PROGRAM IN PROF. DR. R. D. KANDOU CENTRAL HOSPITAL, MANADO - INDONESIA}

1J Wantania, ${ }^{2} 0$ Waworuntu*. 'Department of Obstetric \& Gynecology - Faculty of Medicine UNSRAT, Prof. Kandou Hospital; ${ }^{2}$ Department of Medical Microbiology - Faculty of Medicine UNSRAT, Prof. Kandou Hospital

\subsection{6/sextrans-2015-052270.624}

Introduction The Human immunodeficiency virus (HIV) infection remains a serious health problem globally. Recently, the Prevention of mother-to-child transmission (PMTCT) programmes have gained meaningful achievements, although not evenly spread especially in resource-constrained settings. This study objective is to determine the prevalence of pregnancy with HIV concerning the characteristics of maternal and perinatal outcomes in Prof. Dr. R. D. Kandou Central Hospital as the national referral hospitals in north-eastern part of Indonesia.

Methods This is a cross sectional study with data collected from medical records at the VCT clinic at Prof. Dr. R. D. Kandou Central Hospital Manado after the implementaton of PMTCT program which is from January 2011-December 2014.

Results During the period there are 17 cases of mother with HIV infection. Patients who consume drugs regularly during pregnancy as much as $93.33 \%$, with an overall undetectable HIV infants. About $70 \%$ were delivered by sectio caesarean method. The rest of $6.67 \%$ were not taking ARVs regularly and resulted with CD4 $<200 / \mathrm{mm}^{3}$ and HIV-infected infants.

Conclusion During the program, numbers of HIV in pregnancy cases were discovered and more MTCT cases were prevented. However a more comprehensive and active strategic approach for the PMTCT programmes need to be taken to prevent HIV infection in infants.

Disclosure of interest statement No grants were received in the development of this study. 